\title{
A descriptive study of syphilis testing in Manitoba, Canada, 2015-2019
}

\author{
Souradet Shaw ${ }^{1 \star}$, Pierre Plourde ${ }^{2,3}$, Penny Klassen ${ }^{4}$, Derek Stein ${ }^{3,4}$
}

\begin{abstract}
Background: In 2018, Manitoba had the highest reported rate of infectious syphilis in Canada, at over three times the national average. Infectious syphilis in Manitoba is centred on young, marginalized heterosexual couples in Winnipeg's inner-city. Subsequently, a public health crisis involving congenital syphilis emerged in Manitoba, just prior to the coronavirus disease 2019 pandemic. Testing and screening (in the case of pregnancy) for syphilis is thought to be an effective measure to reduce the incidence of syphilis and its sequelae. The aim of this study is to describe syphilis testing practices in the general population and amongst pregnant women, during a period of shifting syphilis epidemiology.
\end{abstract}

Methods: We used population-based syphilis testing data from Cadham Provincial Laboratory (Winnipeg, Manitoba) for 2015 to 2019. Directly age-standardized rates are reported, and Poisson regression used to model the determinants of testing rates. Rates of prenatal screening are also reported.

Results: From 2015 to 2019 , a total of 386,350 individuals were tested for syphilis. The rate increased annually, from 462 per 10,000 population in 2015 to 704 per 100,000 in 2019, while the female-to-male ratio decreased from 1.8 to 1.6 . Prior to 2019 , the majority of pregnant women (approximately 60\%) were screened once, during the first trimester; however, 2019 saw more women having more than two tests during the course of their pregnancy.

Conclusion: An overall increase in the number of individuals tested was observed, reflecting the increased rate of syphilis in Manitoba. Prenatal screening patterns shifted in 2019, likely in response to rising congenital syphilis numbers.
This work is licensed under a Creative Commons Attribution 4.0 International License.

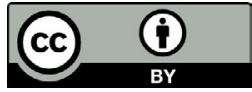

Affiliations

${ }^{1}$ Institute for Global Public Health, Department of Community Health Sciences, University of Manitoba, Winnipeg, MB

2 Population and Public Health, Winnipeg Regional Health Authority, Winnipeg, MB

${ }^{3}$ Department of Medical Microbiology, University of Manitoba, Winnipeg, MB

${ }^{4}$ Cadham Provincial Laboratory, Winnipeg, MB

\section{*Correspondence:}

souradet.shaw@umanitoba.ca

Suggested citation: Shaw SY, Plourde PJ, Klassen P, Stein D. A descriptive study of syphilis testing in Manitoba, Canada, 2015-2019. Can Commun Dis Rep 2022;48(2/3):95-101. https://doi.org/10.14745/ccdr.v48i23a07

Keywords: syphilis, testing, prenatal, surveillance

\section{Introduction}

Over the last decade, North America has seen an increase in the burden of infectious syphilis, the sexually transmitted infection caused by the bacterium Treponema pallidium (T. pallidium) (1-3). Between 2014 and 2018, crude infectious syphilis rates in Canada increased by 153\%; from 7 to 17 per 100,000 population (4). Similarly, in the United States, total case counts for infectious syphilis in $2018(N=35,063)$ were the highest observed since 1991, for a rate of 11 per 100,000 population; for an increase of $70 \%$ since 2014 (2). Although the resurgence of infectious syphilis was first observed primarily amongst gay, bisexual and other men who have sex with men (gbMSM) globally, the epidemic has subsequently spread to heterosexual populations marked by structural issues such as substance use, incarceration and poverty. This has resulted in a notable increase amongst women $(2,5)$, which poses serious challenges to public health in terms of prevention, intervention and follow-up $(5,6)$.

Sequelae of syphilis include neurosyphilis, which can be present during any stage of syphilis $(4,7)$, and congenital syphilis-with potentially catastrophic outcomes for the infant which can also occur in pregnant individuals (8-10). Any occurrence of congenital syphilis in high-income countries is considered a sentinel event and is considered to be a "needless tragedy" $(8,11)$. Increased congenital syphilis cases have been observed across North America $(2,4,12,13)$, as the incidence of congenital syphilis is associated with the prevalence of infectious syphilis in women of reproductive age (2). 
Evidence supports the screening of pregnant women as a highly effective and cost-efficient method to reduce the incidence of congenital syphilis $(14,15)$. Screening and testing of non-pregnant adult and adolescent populations vulnerable to syphilis has also been recommended (16). In vulnerable populations, mathematical modelling has shown that syphilis screening programs with high coverage and intensity can reduce incidence (17), while suboptimal screening for syphilis has been associated with higher equilibrium incidence (18). Although studies have demonstrated high rates of prenatal screening in high-income countries, like the United States, high rates of screening may not be generalizable to broader (non-insured) populations, or to other countries (19). Thus, screening remains a recommended tool in the public health approach against syphilis; however, there is a dearth of population-based studies on actual rates of syphilis screening and testing, and how they may have changed in response to growing syphilis epidemics.

In 2018, Manitoba reported the highest rate of infectious syphilis in Canada, at 61 per 100,000 population (4), and was also on track to have the highest number of congenital syphilis cases (20). Given the lack of population-based studies on syphilis screening and test rates, along with increases in infectious syphilis and concern regarding its sequelae, we sought to describe syphilis testing practices in the general population, and amongst pregnant women during a period of shifting syphilis epidemiology.

\section{Methods}

\section{Data sources}

All syphilis testing in Manitoba is performed at Cadham Provincial Laboratory (CPL). Testing for sexually transmitted and bloodborne infections is provided free of charge for Manitobans (21). For routine syphilis screening and diagnosis, a reverse algorithm is used at CPL. Screening consists of an initial chemiluminescent assay for IgG and IgM antibodies to Treponemal antigens. Positive screening results are further tested by quantitative Rapid Plasma Reagin or Venereal Disease Research Laboratory testing for infectious syphilis. New positive cases receive an additional T. pallidum particle agglutination test as a confirmatory test. Manitoba also offers a prenatal screening program, which offers serological screening for a number of sexually transmitted and bloodborne infections.

In response to the growing number of congenital syphilis cases, provincial guidelines for syphilis screening of pregnant persons were revised to recommend screening at the first visit, 28-32 weeks, and delivery for all pregnant persons and monthly screening for persons with newly diagnosed syphilis that was treated during the current pregnancy. In addition, guidelines recommend screening for other sexually transmitted and bloodborne infections in the first trimester, including HIV, gonorrhea, chlamydia, and hepatitis B and C, when indicated.

\section{Definitions}

\section{Routine testing}

The laboratory received date was used to pull all syphilis tests from January 1, 2015 to December 31, 2019; this date was used to define year of testing. An individual was counted once in a calendar year, with the earliest test used as the index date; age at index date was used to define age groups. Population data were provided by Manitoba Health, Seniors and Active Living. The crude testing rate was calculated using the appropriate mid-point population as the denominator; the number of individuals was counted in the numerator. Cases missing any information on sex, age and region were excluded from analyses (accounting for less than $1 \%$ of the cases). Where appropriate, rates were stratified by regional health authority (RHA), administrative geographic areas constructed for the purposes of healthcare delivery. In Manitoba, there are a total of five RHAs (with 2020 populations reported) (22): Winnipeg Regional Health Authority (WRHA; $n=791$,284); Southern Health-Santé Sud (SH-SS: $n=211,896)$; Prairie Mountain Health $(\mathrm{PMH} ; \mathrm{n}=172,641)$; Interlake-Eastern Regional Health Authority (IERHA; $n=133,834$ ); and Northern Regional Health Authority (NRHA; $n=77,283)$.

\section{Prenatal testing}

Frequency of prenatal syphilis testing was based on the number of unique women giving birth per year, based on the date of delivery. For any given year, the number of women tested during each trimester was "back-calculated" using the date of delivery, with gestational age on the delivery record used to calculate trimesters. Weeks $0-13$ were used to denote the first trimester; weeks $14-27$ the second and 28 or more weeks the third trimester. The age of the mother was that on the date of delivery.

\section{Analyses}

For analyses describing routine syphilis testing, rates were agestandardized to the Canadian population from the 2012 Census; $95 \%$ confidence intervals $(95 \% \mathrm{Cl})$ were generated $(23)$. Poisson regression models, with the logarithm of the population entered as an offset, were used to produce unadjusted and adjusted rate ratios and $95 \% \mathrm{Cls}$. Age group, sex and year of test were included in regression models. Crude annual rate of change was calculated using Poisson regression models. For prenatal screening, the number of women in Manitoba, by RHA and age group, was used in the denominator for age-specific calculations. The $95 \% \mathrm{Cls}$ were estimated using the exact binomial distribution. Only women between 10 and 59 years of age were included in the numerator and denominator for prenatal screening calculations.

\section{Results}

In the five-year period from 2015-2019, a total of 485,808 syphilis tests were performed at CPL, representing 386,735 individuals tested. Excluding those with missing information 
1.6. The ratio of samples to patients increased an average of $17 \%$ (from 1.15 to 1.35 ) from 2015 to 2019. Figure 2 shows changes in age-standardized testing rates by RHA, over the study period. Although at the provincial level rates increased from 2015 to 2019, this increase was heterogeneous across RHAs; the largest increases were observed in NRHA and WRHA, while the rates in SH-SS stayed relatively similar across the study period. (on geography, sex and age), a total of 475,231 tests were
performed on 386,350 unique individuals. Increases in testing were observed every year (Table 1 and Figure 1). In 2015, a total of 62,252 individuals were tested (age-standardized rate: 461.5 per 10,000 population [95\% Cl: $457.8-465.1$ ]); this increased to 94,578 individuals in 2019 (703.7 per 10,000 population; $95 \% \mathrm{Cl}$ : 699.2-708.2). This amounted to an annual increase of $10.5 \%$ over the study period $(p<0.0001)$, while the annual female-to-male testing ratio decreased from 1.8 to

Table 1: Frequency, age-standardized rates (per 10,000 population) and $95 \% \mathrm{Cl}$, all syphilis testing performed at Cadham Provincial Laboratory, by sex, Manitoba (2015-2019)

\begin{tabular}{|c|c|c|c|c|c|c|c|c|c|c|}
\hline \multirow{3}{*}{ Determinants } & \multicolumn{3}{|c|}{ Female } & \multicolumn{3}{|c|}{ Male } & \multicolumn{3}{|c|}{ Total } & \multirow{3}{*}{$\begin{array}{l}\text { Female-to- } \\
\text { male ratio }\end{array}$} \\
\hline & \multirow{2}{*}{ Number } & \multicolumn{2}{|c|}{ Age-standardized } & \multirow{2}{*}{ Number } & \multicolumn{2}{|c|}{ Age-standardized } & \multirow{2}{*}{ Number } & \multicolumn{2}{|c|}{ Age-standardized } & \\
\hline & & Rate & $95 \% \mathrm{Cl}$ & & Rate & $95 \% \mathrm{Cl}$ & & Rate & $95 \% \mathrm{Cl}$ & \\
\hline \multicolumn{11}{|l|}{ Year } \\
\hline 2015 & 40,333 & 599.2 & $593.4-605.1$ & 21,919 & 327.2 & $322.9-331.6$ & 62,252 & 461.5 & $457.8-465.1$ & 1.83 \\
\hline 2016 & 45,952 & 682.7 & $676.5-689.0$ & 24,842 & 371.5 & $366.9-376.2$ & 70,794 & 525.1 & $521.2-529.0$ & 1.84 \\
\hline 2017 & 48,831 & 726.0 & $719.6-732.5$ & 27,182 & 407.2 & $402.4-412.1$ & 76,013 & 564.4 & $560.4-568.5$ & 1.78 \\
\hline 2018 & 51,967 & 773.1 & $766.5-779.8$ & 30,746 & 461.1 & $456.0-466.3$ & 82,713 & 615.0 & $610.8-619.2$ & 1.68 \\
\hline 2019 & 58,499 & 871.4 & $864.3-878.5$ & 36,079 & 540.8 & $535.2-546.4$ & 94,578 & 703.7 & $699.2-708.2$ & 1.61 \\
\hline Total & 245,582 & 730.5 & $727.6-733.4$ & 140,768 & 421.6 & $419.2-423.8$ & 386,350 & 573.9 & $572.1-575.7$ & 1.73 \\
\hline Rate of change ${ }^{b}$ & N/A & $9.1 \%$ & $8.8 \%-9.4 \%$ & N/A & $13.1 \%$ & $12.6 \%-13.5 \%$ & N/A & $10.5 \%$ & $10.3 \%-10.8 \%$ & N/A \\
\hline
\end{tabular}

Abbreviations: $\mathrm{Cl}$, confidence intervals; N/A, not applicable

a Counts include total number of tests performed. 2012 Canadian population (from Statistics Canada) used as standard population

${ }^{b}$ Calculated by Poisson Regression using crude rates

Figure 1: Age-standardized rates (per 10,000 population), individuals tested for syphilis in Manitoba, by sex and year $(2015-2019, \mathrm{~N}=386,350)^{\mathrm{b}}$

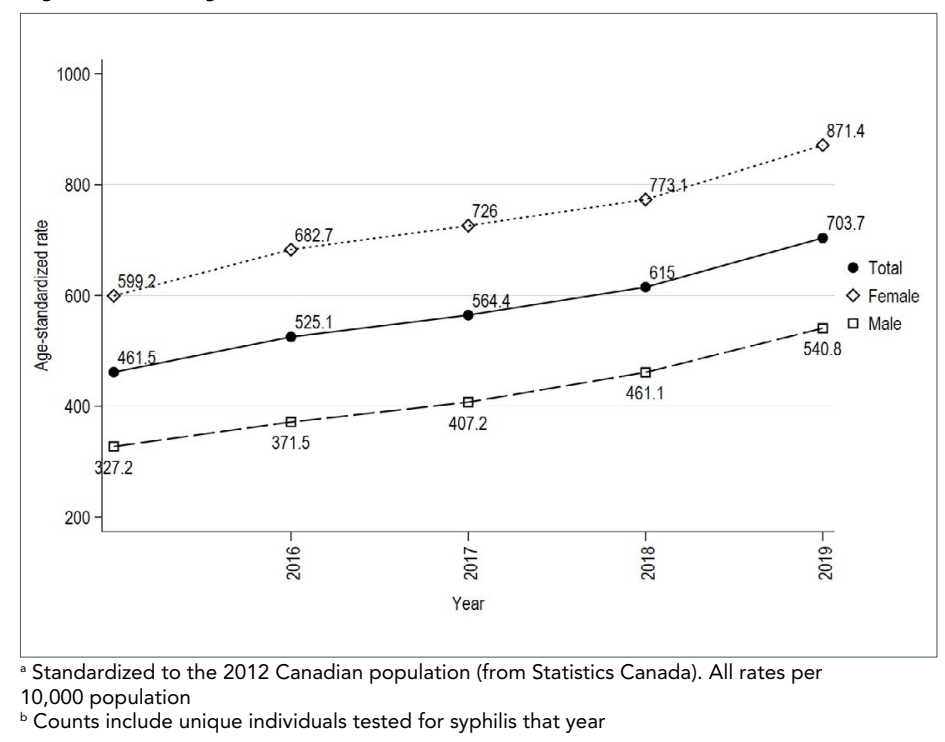

Figure 2: Heatmap of age-standardized rates (per 10,000 population), individuals tested for syphilis in Manitoba, by Regional Health Authority and year (2015-2019, N=386,350)

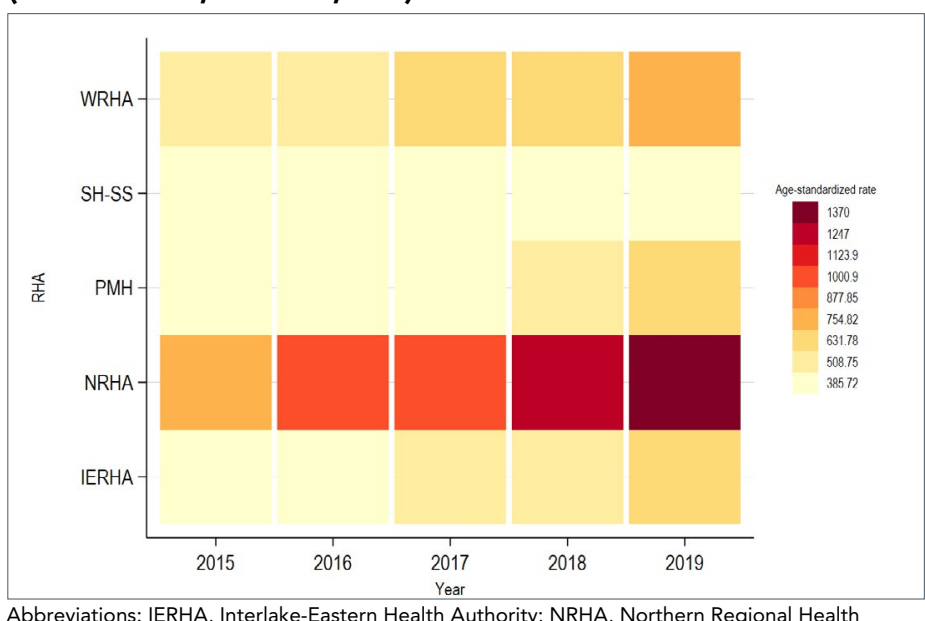

Abbreviations: IERHA, Interlake-Eastern Health Authority; NRHA, Northern Regional Health Authority; PMH, Prairie Mountain Health; RHA, Regional Health Authority; SH-SS, Southern Health-Sante Sud; WRHA, Winnipeg Regional Health Authority 
Results from multivariable Poisson regression demonstrated that adjusted for all other variables in the model, males tested at slightly more than half the rate of females (adjusted relative risk $[A R R]: 0.57,95 \% \mathrm{Cl}: 0.56-0.57$; Table 2); the number of individuals tested for syphilis in 2019 increased by $50 \%$, compared with 2015 (ARR: 1.52, 95\% Cl: 1.50-1.53); and testing rates amongst those 25-29 years of age were twofold higher relative to those 15-19 years of age (ARR: 1.99, 95\% Cl: 1.97-2.02). A time by sex interaction (not shown) revealed a significant interaction between year and sex $(p<0.0001)$, suggesting that the proportion of men testing, relative to women increased over time.

Over the course of the study period, approximately 77,000 women received a prenatal syphilis test, with the annual number of tests stable at around 15,500 women per year (not shown).
Table 3 shows age and region-specific prenatal screening test rates; the per capita screening rate amongst women 10-59 years of age was 294.2 per 10,000 (95\% Cl: 292.2-296.3) from 2015 to 2019. Screening rates were highest in NRHA (487 (95\% Cl: 476-497) per 10,000), and lowest in IERHA (262 [95\% Cl: 256-269] per 100,000). There was a gradient in age-specific rates across RHAs, with the highest age-specific rates in the 25-39 year old age group, with the exception of NRHA. Within NRHA, the highest age-specific rate was seen in the 15-24 year old age group, at 1,184 (95\% Cl: 1,148-1,220) per 10,000 . This was the highest age-specific prenatal syphilis screening rate across all age group and RHA-strata in our study. Through a series of Venn diagrams, Figure 3 shows the distribution of prenatal tests, by trimester. Up until 2018, the majority of women who delivered received only one prenatal syphilis screening test, and this test was done during their first

Table 2: Crude rate (per 10,000 population), unadjusted and adjusted relative risks and $95 \% \mathrm{Cl}$ from Poisson regression, determinants of syphilis testing, Manitoba (2015-2019)

\begin{tabular}{|c|c|c|c|c|c|c|}
\hline Determinants & \multicolumn{2}{|c|}{ Crude rate } & URR & $95 \% \mathrm{Cl}$ & ARR & $95 \% \mathrm{Cl}$ \\
\hline \multicolumn{7}{|l|}{ Sex } \\
\hline Female & 719.6 & $716.7-722.2$ & Ref & $\mathrm{N} / \mathrm{A}$ & Ref & $\mathrm{N} / \mathrm{A}$ \\
\hline Male & 417.5 & $415.3-419.7$ & 0.58 & $0.58-0.58$ & 0.57 & $0.56-0.57$ \\
\hline \multicolumn{7}{|l|}{ Year } \\
\hline 2015 & 458.8 & $455.2-462.4$ & Ref & $\mathrm{N} / \mathrm{A}$ & Ref & N/A \\
\hline 2016 & 521.7 & $517.9-525.6$ & 1.14 & $1.13-1.15$ & 1.14 & $1.13-1.15$ \\
\hline 2017 & 560.2 & $556.2-564.2$ & 1.22 & $1.21-1.23$ & 1.22 & $1.21-1.23$ \\
\hline 2018 & 609.6 & $605.4-613.7$ & 1.33 & $1.32-1.34$ & 1.33 & $1.31-1.34$ \\
\hline 2019 & 697.0 & $692.5-701.4$ & 1.52 & $1.51-1.53$ & 1.52 & $1.50-1.53$ \\
\hline \multicolumn{7}{|l|}{ Age group } \\
\hline Younger than 15 & 37.3 & $36.2-38.3$ & 0.04 & $0.04-0.05$ & 0.04 & $0.04-0.05$ \\
\hline $15-19$ & 841.8 & $833.1-850.5$ & Ref & $\mathrm{N} / \mathrm{A}$ & Ref & N/A \\
\hline $20-24$ & $1,491.0$ & $1,480.2-1,502.0$ & 1.77 & $1.75-1.79$ & 1.77 & $1.75-1.79$ \\
\hline $25-29$ & $1,694.0$ & $1,682.5-1,705.6$ & 2.01 & $1.99-2.04$ & 1.99 & $1.97-2.02$ \\
\hline $30-39$ & $1,208.6$ & $1,201.5-1,215.7$ & 1.44 & $1.42-1.45$ & 1.42 & $1.40-1.44$ \\
\hline $40-49$ & 467.8 & $463.2-472.5$ & 0.56 & $0.55-0.56$ & 0.55 & $0.54-0.56$ \\
\hline 50 or older & 168.3 & $166.7-170.0$ & 0.20 & $0.20-0.20$ & 0.20 & $0.19-0.20$ \\
\hline
\end{tabular}

Abbreviations: ARR, adjusted relative risk; $\mathrm{Cl}$, confidence intervals; N/A, not applicable; Ref, reference; URR, unadjusted relative risk

Table 3: Frequency and age-specific rates (per 10,000) of prenatal syphilis testing, Manitoba women (10-59 years old), by age group and Regional Health Authority (2015-2019)

\begin{tabular}{|c|c|c|c|c|c|c|c|c|c|c|c|c|c|c|c|}
\hline \multirow{2}{*}{$\begin{array}{c}\text { Age } \\
\text { group } \\
\text { (years) }\end{array}$} & \multicolumn{3}{|c|}{ WRHA } & \multicolumn{3}{|c|}{ PMH } & \multicolumn{3}{|c|}{ IERHA } & \multicolumn{3}{|c|}{ NRHA } & \multicolumn{3}{|c|}{ SH-SS } \\
\hline & Number & Rate & $\begin{array}{c}95 \% \\
\mathrm{Cl}\end{array}$ & Number & Rate & $\begin{array}{c}95 \% \\
\mathrm{Cl}\end{array}$ & Number & Rate & $\begin{array}{c}95 \% \\
\mathrm{Cl}\end{array}$ & Number & Rate & $\begin{array}{c}95 \% \\
\mathrm{Cl}\end{array}$ & Number & Rate & $\begin{array}{c}95 \% \\
\mathrm{Cl}\end{array}$ \\
\hline $\begin{array}{l}\text { Younger } \\
\text { than } 15\end{array}$ & 33 & 1.0 & $\begin{array}{r}0.7- \\
1.5 \\
\end{array}$ & 11 & 1.4 & $\begin{array}{r}0.7- \\
2.5 \\
\end{array}$ & 13 & 2.3 & $\begin{array}{r}1.3- \\
4.0 \\
\end{array}$ & 59 & 10.6 & $8.1-13.7$ & 13 & 1.1 & $0.6-2.0$ \\
\hline $15-24$ & 6,465 & 264.3 & $\begin{array}{r}258.0- \\
270.7\end{array}$ & 2,386 & 464.5 & $\begin{array}{r}446.4- \\
483.0\end{array}$ & 1,936 & 500.4 & $\begin{array}{r}478.9- \\
522.6\end{array}$ & 3,595 & $1,184.0$ & $\begin{array}{r}1,147.8- \\
1,220.8\end{array}$ & 3,679 & 529.0 & $\begin{array}{r}512.5- \\
545.9\end{array}$ \\
\hline $25-39$ & 32,912 & 766.2 & $\begin{array}{r}758.2- \\
774.2\end{array}$ & 6,704 & 819.0 & $\begin{array}{r}800.3- \\
838.0\end{array}$ & 4,155 & 782.3 & $\begin{array}{r}759.6- \\
805.5\end{array}$ & 4,387 & $1,107.1$ & $\begin{array}{r}1,076.4- \\
1,138.4\end{array}$ & 9,289 & 945.9 & $\begin{array}{r}927.6- \\
964.3\end{array}$ \\
\hline $\begin{array}{l}40 \text { or } \\
\text { older }\end{array}$ & 1,107 & 21.5 & $\begin{array}{r}20.3- \\
22.8 \\
\end{array}$ & 152 & 14.5 & $\begin{array}{r}12.3- \\
17.0 \\
\end{array}$ & 101 & 11.3 & $\begin{array}{l}9.2- \\
13.7 \\
\end{array}$ & 101 & 24.2 & $\begin{array}{r}19.7- \\
29.4 \\
\end{array}$ & 275 & 22.8 & $\begin{array}{r}20.2- \\
25.6 \\
\end{array}$ \\
\hline Total & 40,517 & 268.9 & $\begin{array}{r}266.3- \\
271.5\end{array}$ & 9,253 & 292.0 & $\begin{array}{r}286.2- \\
297.9\end{array}$ & 6,205 & 262.2 & $\begin{array}{r}255.8- \\
268.7\end{array}$ & 8,142 & 486.5 & $\begin{array}{r}476.2- \\
496.9\end{array}$ & 13,256 & 329.7 & $\begin{array}{r}324.2- \\
335.3\end{array}$ \\
\hline
\end{tabular}

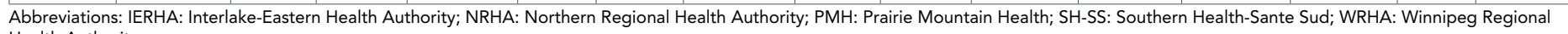
Health Authority

a Counts include unique individuals screened for syphilis that year

Page $98 \quad$ CCDR • February/March $2022 \bullet$ Vol. 48 No. 2/3 
Figure 3: Prenatal syphilis testing patterns, by trimester and year of infant birth, Manitoba women 2015-2019

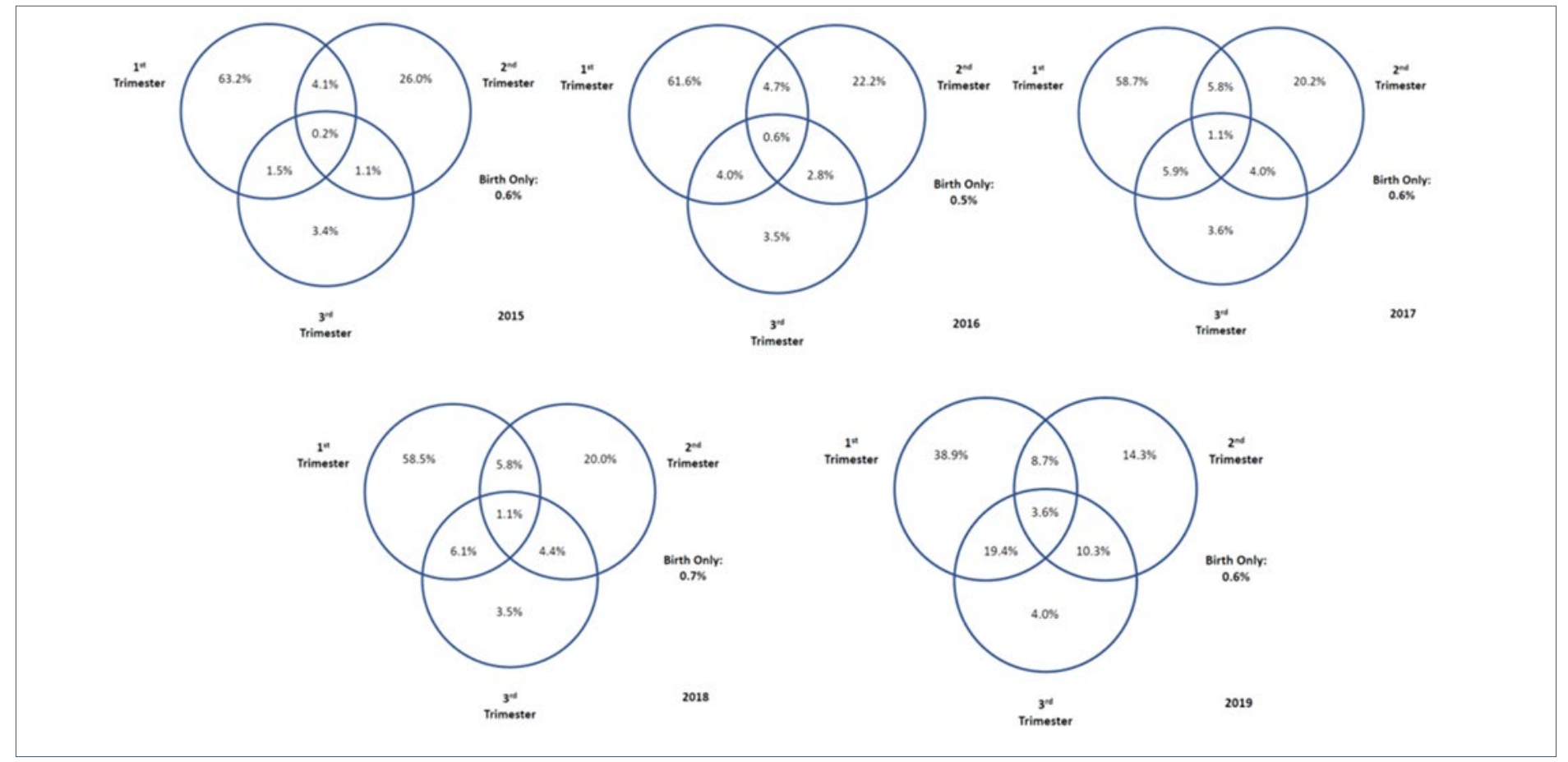

trimester; from 2015 to 2018 , this proportion ranged between $59 \%-63 \%$. During this period, approximately $1 \%$ received at least one screening test in all three trimesters. A substantial shift in testing patterns was observed in 2019, with only $39 \%$ of women now receiving a screening test during their first trimester. The proportion receiving testing in the first and third trimesters increased from $1.5 \%$ in 2015 to $19 \%$ 2019. Similarly, the proportion receiving tests in both the second and third trimesters increased from $1.1 \%$ to $10 \%$ between 2015 and 2019 . Finally, approximately $3.6 \%$ of women aged $10-59$ years of age and who delivered in 2019 had a prenatal syphilis test in all three trimesters, a 20-fold increase from 2015.

\section{Discussion}

According to the Public Health Agency of Canada, while Canada as a whole showed a $153 \%$ increase in infectious syphilis rates between 2014 and 2018, Manitoba showed a 560\% increase during the same time period (4). A recent study observed increasing rates of syphilis amongst women in Winnipeg as early as 2014 , with outbreaks among young women associated with living in the inner-city, substance use and being co-infected with chlamydia (5). At the time of the study, although $24 \%$ of the women reported being pregnant, no congenital syphilis cases were detected (5). Subsequent to this study, Manitoba reported its first case of congenital syphilis in over 50 years in 2015 and another case was identified in 2017 (4). Congenital syphilis cases in Manitoba grew dramatically since that time, with at least 30 cases reported in 2020 in Winnipeg alone, for a crude rate of 3.5 per 1,000 live births (13).
Manitoba Health, Seniors and Active Living recommended that all pregnant women be screened for syphilis during their first prenatal visit (24); however, vertical transmission of syphilis can occur despite existing prenatal screening programs, as women can become infected between testing and delivery, and a diagnosis of syphilis may be missed by clinicians due to its non-specific clinical manifestations $(12,14)$. Our results show a recent and substantial change in prenatal screening practice, with the proportion of women having only one test during pregnancy decreasing from $93 \%$ in 2015 to $57 \%$ in 2019 . Conversely, the proportion of women having two or more tests increased from 7\% in 2015 to $43 \%$ in 2019. Given the expanding syphilis epidemic in Manitoba, an even larger increase in screening rates in the third trimester could lead to the detection of more cases of congenital syphilis. Of some concern is the persistent proportion of women whose health records indicated the only prenatal screening they received was at the time of delivery. This proportion ranged from $0.5 \%-0.7 \%$ in any given year and over the course of the study period, amounted to approximately 400 women. Furthermore, recent evidence suggested a significant impact of the coronavirus disease 2019 (COVID-19) pandemic on testing rates and clinic visits for sexually transmitted and bloodborne infections in North America (25-27); for syphilis, this may have resulted in an increasing proportion of undiagnosed syphilis, leading to increased congenital syphilis. Monitoring of prenatal syphilis screening rates is thus critical to the goal of eliminating congenital syphilis. The United States Centers for Disease Control and Prevention suggested testing be offered in a variety of modalities, including walk-in clinics, telehealth and self-testing kits (28). Given the availability of population-based 
testing data in Manitoba, future research should explore the impact of the COVID-19 pandemic on testing rates of syphilis and other sexually transmitted and bloodborne infections, and describe whether certain sub-populations were more likely to be impacted. The shift from gbMSM to heterosexual transmission of syphilis likely played a role in the declining female-to-male ratio, with both gbMSM and heterosexual men more likely to test for syphilis. This was supported by the year by sex interaction being statistically significant in regression models; monitoring trends in syphilis testing in males, before and after the arrival of COVID-19 will be an important surveillance objective.

Aside from congenital syphilis, another consequence of infectious syphilis is neurosyphilis, with the rise in incident syphilis infections in Manitoba expected to produce an increase in the number of neurosyphilis cases. A review of neurosyphilis cases in Alberta, Canada found approximately 30 cases of early and late neurosyphilis annually between 2015 and 2016 (7). Program data from CPL have reported 23 and 28 (up to September 2019) lab-detected neurosyphilis cases in 2018 and 2019, respectively, based on reactive cerebrospinal fluid-Venereal Disease Research Laboratory tests conducted with non-bloody cerebrospinal fluid (Stein, personal communication). Landry et al. found clear socio-demographic differences between those diagnosed with early and late neurosyphilis (7). Early neurosyphilis cases were more likely to be male, to be born in Canada, to be Caucasian and to report having sex with other men; in contrast, late neurosyphilis cases were also more likely to be male, but to be born outside of Canada and to identify as heterosexual (7). Future surveillance efforts to detect neurosyphilis are highly recommended.

\section{Strengths and limitations}

A strength of our study was that it was population-based; thus, testing rates were not restricted to certain sub-populations. Limitations include limited demographic, clinical and epidemiological information; further research should link individuals to other administrative healthcare datasets. Due to limitations in accessing incident syphilis rates, testing rates were not compared with incidence of syphilis by RHA; however, NRHA and WRHA have historically reported the highest rates of infectious syphilis (29).

\section{Conclusion}

Our results demonstrate that the number of individuals testing for syphilis increased between 2015 and 2019. Within Manitoba, increasing incidence of infectious syphilis received significant media exposure, while public health alerted practitioners to the necessity of syphilis screening (4); both media and public health communications likely contributed to increased testing rates. Future research should explore whether testing and screening are reaching the most appropriate populations, especially given the increases in congenital syphilis cases observed in Winnipeg.

\section{Authors' statement}

SYS - Conceptualized analyses, performed statistical analysis, and wrote the first draft of the manuscript

PJP — Interpreted findings and revised the manuscript critically for intellectual content

PK - Designed the extraction process, acquired data, performed initial statistical analyses and contributed to manuscript revisions

DS - Conceptualize analyses, interpreted findings and revised the manuscript critically for intellectual content

Each author met the ICMJE criteria for authorship. All authors approved the final version of the manuscript.

The content and view expressed in this article are those of the authors and do not necessarily reflect those of the Government of Canada.

\section{Competing interests}

None.

\section{Acknowledgements}

None.

\section{Funding}

SYS was supported by a Canada Research Chair in Program Science and Global Public Health (Tier II).

\section{References}

1. Choudhri Y, Miller J, Sandhu J, Leon A, Aho J. Infectious and congenital syphilis in Canada, 2010-2015. Can Commun Dis Rep 2018;44(2):43-8. DOI PubMed

2. Centers for Disease Control and Prevention. Sexually Transmitted Disease Surveillance 2018. Atlanta (GA): CDC; 2019. https://www.cdc.gov/std/stats18/ STDSurveillance2018-full-report.pdf

3. Public Health Agency of Canada. Report on Sexually Transmitted Infections in Canada, 2017. Ottawa (ON): PHAC; 2019. https://www.canada.ca/en/public-health/ services/publications/diseases-conditions/report-sexuallytransmitted-infections-canada-2017.html

4. Public Health Agency of Canada. Syphilis in Canada: Technical Report on Epidemiological Trends, Determinants and Interventions. Ottawa (ON): PHAC; 2020. https:// www.canada.ca/en/services/health/publications/diseasesconditions/syphilis-epidemiological-report.html

5. Shaw SY, Ross C, Nowicki DL, Marshall S, Stephen S, Davies C, Riddell J, Bailey K, Elliott LJ, Reimer JN, Plourde PJ. Infectious syphilis in women: what's old is new again? Int J STD AIDS 2017;28(1):77-87. DOI PubMed 
6. Kidd SE, Grey JA, Torrone EA, Weinstock HS. Increased Methamphetamine, Injection Drug, and Heroin Use Among Women and Heterosexual Men with Primary and Secondary Syphilis - United States, 2013-2017. MMWR Morb Mortal Wkly Rep 2019;68(6):144-8. DOI PubMed

7. Landry T, Smyczek P, Cooper R, Gratrix J, Bertholet L, Read R, Romanowski B, Singh AE. Retrospective review of tertiary and neurosyphilis cases in Alberta, 1973-2017. BMJ Open 2019 Jun;9(6):e025995. DOI PubMed

8. Kamb ML, Newman LM, Riley PL, Mark J, Hawkes SJ, Malik T, Broutet N. A road map for the global elimination of congenital syphilis. Obstet Gynecol Int 2010;2010:312798. DOI PubMed

9. Shahrook S, Mori R, Ochirbat T, Gomi H. Strategies of testing for syphilis during pregnancy. Cochrane Database Syst Rev 2014;10(10):CD010385. DOl PubMed

10. World Health Organization. The global elimination of congenital syphilis: rationale and strategy for action. Geneva (CH): WHO; 2007. https://www.who.int/reproductivehealth/ publications/rtis/9789241595858/en/

11. ProMED. Syphilis - USA (09): (CA) pregnant women, congenital, rising incidence. Archive \#20150715.3512635. July 14, 2015. http://www.promedmail.org/ post/20150715.3512635

12. Keuning MW, Kamp GA, Schonenberg-Meinema $D$, Dorigo-Zetsma JW, van Zuiden JM, Pajkrt D. Congenital syphilis, the great imitator-case report and review. Lancet Infect Dis 2020;20(7):e173-9. DOI PubMed

13. Benoit P, Tennenhouse LG, Lapple A, Hill-Carroll G, Shaw SY, Bullard J, Plourde P. Congenital syphilis re-emergence in Winnipeg, Manitoba. Can Commun Dis Rep 2022;48(2/3):89-94. DOI

14. Lin JS, Eder ML, Bean SI. Screening for Syphilis Infection in Pregnant Women: Updated Evidence Report and Systematic Review for the US Preventive Services Task Force. JAMA 2018;320(9):918-25. DOl PubMed

15. U.S. Preventive Services Task Force. Screening for syphilis infection in pregnancy: U.S. Preventive Services Task Force reaffirmation recommendation statement. Ann Intern Med 2009;150(10):705-9. DOI PubMed

16. Bibbins-Domingo K, Grossman DC, Curry SJ, Davidson KW, Epling JW Jr, García FA, Gillman MW, Harper DM, Kemper AR, Krist AH, Kurth AE, Landefeld CS, Mangione CM, Phillips WR, Phipps MG, Pignone MP; US Preventive Services Task Force (USPSTF). Screening for Syphilis Infection in Nonpregnant Adults and Adolescents: US Preventive Services Task Force Recommendation Statement. JAMA 2016;315(21):2321-7. DOI PubMed

17. Tuite AR, Shaw S, Reimer JN, Ross CP, Fisman DN, Mishra S. Can enhanced screening of men with a history of prior syphilis infection stem the epidemic in men who have sex with men? A mathematical modelling study. Sex Transm Infect 2018;94(2):105-10. DOI PubMed
18. Tuite A, Fisman D. Go big or go home: impact of screening coverage on syphilis infection dynamics. Sex Transm Infect 2016;92(1):49-54. DOI PubMed

19. Neblett Fanfair R, Tao G, Owusu-Edusei K, Gift TL, Bernstein KT. Suboptimal Prenatal Syphilis Testing Among Commercially Insured Women in the United States, 2013. Sex Transm Dis 2017;44(4):219-21. DOl PubMed

20. CBC News. 10 infants infected with syphilis as outbreak worsens. Feb 25, 2019. https://www.cbc.ca/news/canada/ manitoba/syphilis-manitoba-outbreak-infants-1.5032422

21. Lix L, Smith M, Azimaee M, Dahl M, Nicol P, Burchill C, Burland E, Goh C, Schultz J, Bailly A. A Systematic Investigation of Manitoba's Provincial Laboratory Data. Winnipeg (MB): MCHP; 2012. http://mchp-appserv.cpe. umanitoba.ca/landing.php?referencePaperID=76804

22. Manitoba Health Seniors and Active Living. Population Report, June 1, 2020. Winnipeg (MB): Government of Manitoba; 2020. https://www.gov.mb.ca/health/population/ pr2020.pdf

23. Tiwari RC, Clegg LX, Zou Z. Efficient interval estimation for age-adjusted cancer rates. Stat Methods Med Res 2006;15(6):547-69. DOI PubMed

24. Manitoba Health Seniors Care. Updates to Syphilis Protocol Congenital Syphilis and Syphilitic Stillbirth Case Definitions and Reporting. Winnipeg (MB): Government of Manitoba; Oct 12, 2021. https://www.gov.mb.ca/health/publichealth/ $\mathrm{cdc/protocol/syphilis.pdf}$

25. Menza TW, Zlot Al, Garai J, Humphrey S, Ferrer J. The Impact of the SARS-CoV-2 Pandemic on Human Immunodeficiency Virus and Bacterial Sexually Transmitted Infection Testing and Diagnosis in Oregon. Sex Transm Dis 2021;48(5):e59-63. DOI PubMed

26. Tao J, Napoleon SC, Maynard MA, Almonte A, Silva E, Toma E, Chu CT, Cormier K, Strong S, Chan PA. Impact of the COVID-19 Pandemic on Sexually Transmitted Infection Clinic Visits. Sex Transm Dis 2021;48(1):e5-7. DOl PubMed

27. Bonett S, Petsis D, Dowshen N, Bauermeister J, Wood SM. The Impact of the COVID-19 Pandemic on Sexually Transmitted Infection/Human Immunodeficiency Virus Testing Among Adolescents in a Large Pediatric Primary Care Network. Sex Transm Dis 2021;48(7):e91-3. DOI PubMed

28. Rogers B, Tao J, Murphy M, Chan PA. The COVID-19 Pandemic and Sexually Transmitted Infections: Where Do We Go From Here? Sex Transm Dis 2021;48(7):e94-6. DOI PubMed

29. Manitoba Health Seniors and Active Living. Sexually Transmitted Infections in Manitoba: 2014. Winnipeg (MB): Government of Manitoba; November 2016. https://www. gov.mb.ca/health/publichealth/surveillance/docs/stim2014. pdf 